\title{
A Regra "Locus Regit Actum"
}

\author{
Cadeira: Direito Internacional Privado \\ Professor: Dr. T. B. Souza Carvalho \\ Aluno: Nicolau Nazo
}

A regra "Locus regit actum", como uma série de outras que constituem hoje principios definitivamente incorporados ao Direito Internacional Privado, teve a sua origem entre os post-glosadores, remontando a Bartolo. (1).

Adotando como criterio a competencia do lugar da sua celebração em relação ao testamento, os estatutarios foram desenvolvendo o alcanoe da regra a diversos outros atos juridicos, até elevarem aquele adagio ás culminancias de um principio, afirmando que a lei reguladora da fórma externa dos atos é a do lugar da sua celebração.

$\mathrm{Na}$ Italia, em consequencia do predominio do direito romano, que era o direito comum, e notadamente na França, onde, em obediencia ao principio da territorialidade dos costumes, se negava valor aos atos celebrados segundo a lex loci fora do territorio regido por aqueles costumes, houve, no começo, dúvidas na aceitação da regra.

Nos seculos XVI e XVII, porém, os estatutarios franceses, a exemplo do que haviam feito muito tempo antes os post-glosadores, admitiram o imperio da lex loci actus. A tese sustentada pela doutrina não demorou em ser aceita pela jurisprudencia a partir do seculo XVI, como se pode 
ver em Lanné (Introduction au Droit International Privé, vol. II, pags. 352-353).

Houve, no entanto, mais tarde, uma nova reação contra a regra "locus regit actum", consubstanciada no Edito perpétuo dos arquiduques Alberto e Izabel, promulgado na Belgica no ano 1611 e cujo artigo 13 dispunha que, no caso em que os costumes não fossem os mesmos em relação ás disposições de última vontade,

“és lieux de résidence des testateurs et de la situation de leurs biens,. en ce qui touche la qualité desdits biens, si on en peut disposer et avec quelles formes et solennités, on suivra les costumes et usances de ladite situation".

Tais foram, porém, as reclamações havidas contra êsse dispositivo que foi êle interpretado no sentido de que as formalidades para as quais o edito exigia a observancia da lex situs deviam entender-se somente as que constituem a substancia do testamento e não as que se referem á redação do ato, para as quais bastaria seguir as leis do lugar em que o testamento era feito.

Os estatutarios holancieses do seculo XVII tambem não

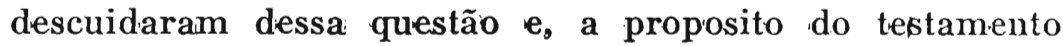
feito segundo as fórmas locais, dizia PAulo Voët que êsse testamento é valido no lugar em que o testador tem o seu domicilio ou possue imoveis. Huber chegava a afirmar que um ato valido $a b$ initio é valido em toda parte.

Como a forma dos atos não podia entrar em nenhuma das duas categorias de estatutos, isto é, nem na de natureza real, nem na de caráter pessoal, Paulo VoËT criou uma nova categoria, a dos estatutos mistos, tendo em mira o seu efeito, classificação essa que foi seguida por Pothier e Froland (2).

Quando se discutiu o Codigo Civil Francês, a regra "locus regit actum" tinha varios seculos de existencia, o que levou Pillet e Niboyet a escrever o seguinte: "On a pu dire qu'elle était considerée comme un article de foi du credo du 
droit français. Elle était bien le type de la règle coutumière par excellence. Le project de l'an VIII la formulait d'une manière générale: - "La forme des actes est reglée par les lois du lieu dans lequel ils sont faits ou passés". Elle disparût au cours des travaux préparatoires. Quoique le Code n'en ait fait que de rares applications au mariage, aux actes de l'état civil et au testament, son maintien n'a jamais été contesté serieusement en doctrine ou en jurisprudence" (3).

Realmente, com exceção de ValÉry (Manuel de Droit International Privé, ns. 391 e s.), que entende que a forma externa dos atos deveria ser determinada pela lei do país em que os mesmos devem produzir os seus efeitos, a doutrina e a jurisprudencia francesas jamais negaram aplicação áquele principio, apesar de sua omissão no Codigo Napoleão, como exuberantemente demonstra, apoiado em larga messe de arestos e farta bibliografia, o professor EugĖNe Audrner, no $\mathrm{X}$ volume do "Répertoire de Droit International" pg. 390.

O Codigo Civil Brasileiro expressamente consignou a regra "locus regit actum" no art. 11 da Introdução, determinando que "A forma extrinseca dos atos, públicos ou particulares, reger-se-á, segundo a lei do lugar em que se praticarem"

Qual o fundamento da regra "locus regit actum"?

Grande é a divergencia que separa os autores na fixação de um conceito que satisfaça não só pela clareza, como pela sua perfeita identidade com o principio.

Segundo Buzzati, em livro classico sobre o assunto, tem-se recorrido á utilidade, á necessidade, á relação entre o ato e o lugar da sua celebração, á submissão voluntária, ao principio dos direitos adquiridos, á ordem pública e ao costume, para justificar o principio (4), não faltando quem: 
lhe atribua um carater de generalidade, compreendida esta na acepção que lhe dá o sistema de Pillet (5).

Variando como varia, de sistema para sistema e quasi de autor para autor, o fundamento da regra, dificil, si não impossivel, seria aferir-se a importancia do principio, si num ponto pelo menos os autores não estivessem de acôrdo. Esse ponto de concordancia no meio de tantas divergencias é $o$ interêsse, a necessidade prática da regra.

Parece-nos, no entanto, que a principal dificuldade para uma perfeita conceituação do fundamento da regra "locus regit actum" reside no fato da maior ou menor extensão dada ao principio, nâo só pela doutrina, como pelos diferentes sistemas legislativos.

Como é sabido, não é pacifica a doutrina em relação ao valor do principio "locus regit actum", caraterizando-o uns como uma regra de direito internacional positivo, entendendo outros que é um principio de competencia ou de suficiencia, discutindo outros o seu caráter obrigatorio ou facultativo.

Diante, pois, dessa diversidade de criterios é logico sejam tambem diferentes as soluções e, como conseqüência natural, variados os fundamentos com que se procura justificar a regra.

Atendendo-se ao fato da generalidade das legislações admitirem o principio, deve-se dai concluir que a regra "locus regit actum" é uma norma de direito internacional positivo, obrigatoria para todos os Estados?

A resposta negativa impõe-se desde logo, tendo em vista que algumas legislações lhe estabelecem restrições, ditadas pela respectiva tradição ou por principios doutrinarios. Mais acertado será dizer-se com Anzilotri que a regra "locus regit actum" é antes uma norma de direito uniforme, tendo cada Estado a faculdade de a aceitar ou não e de modificá-la como entender.

$\mathrm{Na}$ doutrina de Savigny, seguida por Dreyfus na sua tese "L'acte juridique en droit privé international", aparece a regra como um principio de suficiencia, pois a lei compe- 
tente para a forma externa dos atos seria a propria lei que deve, de modo geral, regular a relação juridica.

Filiaram-se a êsse critério a lei de introdução ao Codigo Civid Alemão (art. 11) e a lei japonesa de 15 de Junho de 1898 (art. 8), estabelecendo a primeira que: “A forma de um ato juridico é determinada pelas leis que regem a relação de direito, que constitue objeto do ato. Basta, entretanto, observar as leis do lugar onde o ato é constituido". Mais ainda, no direito alemão é excluida a regra facultativa "locus regit actum" quando se trata da constituição ou da transferência de direitos reais sôbre as cousas, moveis ou imoveis, casos em que se aplica exclusivamente a lex rei sitae.

$\mathrm{Na}$ sistemática do direito germânico, a que se filia a lei japonesa, aparece, assim, como regra fundamental da forma dos atos em direito internacional privado a lex contractus e como exceção, com caráter facultativo, a regra "locus regit actum".

Atribuem á referida regra o valor de um principio de competencia os escritores que procuram o fundamento da mesma ou na relação existente entre o ato juridico e o lugar onde é praticado ou na consideração de que as leis de forma são leis de ordem publica, dizendo Machado Vilela que a mesma orientação seguem as legislações que mandam regular a forma externa dos atos pela lei do lugar da celebração, sem reconhecerem a legitimidade da observancia de outra lei (6).

Segundo o ilustre professor da Universidade de Coimbra, a êste último grupo pertence a legislação portuguesa (Codigo Civil, art. 24, e Codigo Comercial, art. $4 .^{\circ}$ n. $\left.3 .^{\circ}\right)$.

Quer na doutrina, quer nas legislações, a regra "locus regit actum" aparece óra como obrigatoria, ora como facultativa, segundo a validade formal do ato depende absolutamente da observancia da lei do lugar da celebração ou se permite a observancia de outra lei. A maioria das legislações considera a regra como facultativa. E' o que se infere da leitura do art. 9..$^{\circ}$ do titulo preliminar do Codigo Civil Italiano, do $11 .^{\circ}$ do Codigo Civil Espanhol, do $12 .^{\circ}$ do Ar- 
gentino e do $11 .^{\circ}$ do Venezuelano, o mesmo podendo dizer-se do direito alemão e japonês.

Cumpre, porém, acentuar, como o fazem com bastante clareza Pillet et Niboyet que: "La règle locus regit actum n'est ni impérative ni facultative a priori. Certains actes doivent obeir à la lex loci actus, d'autres peuvent être faits conformément à une autre loi" (Manuel, cit. pag. 492).

$\mathrm{E}$ exemplificam com os atos autenticos feitos por um oficial público do lugar do ato, não podendo êste, na redação e constituição do ato, afastar-se das disposições da sua lei, salvo quando o legislador de seu país o autorizou expressamente a adotar outra lei diferente, como se deu na França, com a lei de 24 de julho de 1910, art. 10, que autorizou os notarios da Alsacia Lorena a lavrar certos atos pela forma notarial local ou pela francesa, de acôrdo com a vontade das partes.

Cessa, porém, o caráter imperativo da regra quando as partes, ambas da mesma nacionalidade, ao invés de procurarem o oficial publico do lugar, se dirigem ao representante diplomatico ou consul de seu país e perante um ou outro concretizam o ato juridico. Nesse caso, a forma externa do ato não será a do lugar da celebração do ato, mas a do país de que o diplomata ou o consul é o representante.

Bosquejados rapidamente o historico e o fundamento da regra "locus regit actum", cumpre-nos agora investigar qual o caráter desse principio no Direito Brasileiro.

A que grupo de legislações pertence a lei brasileira?

Ao das que consideram a regra como imperativa, isto é, não admitindo a interferencia de qualquer outra lei que não seja a do lugar da celebração do ato, ou ao das que entendem que o principio é facultativo e, portanto, permitindo que o ato possa revestir tanto a forma externa deter- 
minada pela lei do lugar da sua celebração, como a forma externa da lei nacional das partes?

Antes de respondermos a estas interrogações, não nos parece fóra de proposito ver o que havia no direito anterior ao Codigo Civil em relação á regra "locus regit actum" e acompanhar os trabalhos parlamentares sôbre a nossa materia.

Embora reconhecendo o principio "locus regit actum", o direito anterior ao Codigo Civil abria as seguintes exceções áquela regra:

$1 .{ }^{\mathrm{a}}$ ) - os atos celebrados por brasileiros em país estrangeiro e em lugar onde houvesse consul brasileiro, para que pudessem produzir efeitos no Brasil, deviam revestir a forma da lei brasileira (Regulamento 737 de 25 de Novembro de 1850, art. $3 .^{\circ}$ par. $2 .^{\circ}$, e decreto 3.084 de 5 de Novembro de 1898 , parte IV, art. $90^{\circ}$ );

2.a) - não produziam efeitos no Brasil os atos praticados em país estrangeiro por brasileiros, em documento particular, quando, pela lei brasileira, a escritura publica fosse da substancia do ato (lei n. 79 de 23 de agosto de 1892, art. 1. par. $2 .^{\circ}$, e art. $2 .^{\circ}$ );

$\left.3 .{ }^{a}\right)$ - os contratos celebrados em país estrangeiro não produziam hipoteca sôbre os bens situados no Brasil, salvo o direito estabelecido em tratados, ou se fossem celebrados entre brasileiros, ou estipulados em favor destes, nos consulados brasileiros, com as solenidades e condições prescritas pela lei brasileira (decreto $\mathrm{n}^{\circ} 1.696$ de 16 de Janeiro de 1890 , art. $4 .^{\circ}$, e decreto $n .^{\circ} 370$ de 2 de Maio de 1890, art. 124). (7).

No projeto Bevilaqua, o atual artigo 11 da Introdução tinha o número 19, e a seguinte redação: "a forma autên- 
tica dos atos públicos ou particulares é regulada pela lei do lugar em que se praticam".

Ao discutir-se êsse artigo na comissão revisora, por indicação dos drs. LACERda e Barradas, foramt substituidas as expressões "forma autêntica" por "forma extrínseca" e "se praticam" por "são praticados" (8).

Deante dessas modificações, o art. 19 ficou com a seguinte redação no projeto revisto: “A forma extrinseca dos atos públicos ou particulares é regulada pela lei do lugar em que são praticados"

Novas emendas, porém, devia sofrer o artigo, tambem de redação, devidas a Ruy Barbosa, as quais, não atingindo a essencia, vieram dar maior elegancia ao preceito legislativo, com a substituição das palavras "é regulada pela lei" pela locução "reger-se-á pela lei" e "se praticarem" por "forem praticados".

Essa foi a redação definitiva, com a qual passou para - Codigo Civil.

Do caráter genérico do dispositivo, das discussões havidas nas comissões, da circunstancia de haver o art. 1.807 do Codigo Civil revogado todas as leis anteriores sobre as materias de direito civil, do sistema do legislador brasileiro formular, ao lado dos principios, as exceções quando as admitiu e do fato do art. 13 da Introdução reproduzir nos ns. I e II os preceitos dos artigos $4 .^{\circ}$ e $50^{\circ}$ do Regulamento 737 de 25 de novembro de 1850, disso tudo conclue Machado Vilela que a regra "locus regit actum" não admite exceções no direito civil brasileiro, e seria, portanto, de caráter imperativo. Cita em seu apoio a opinião de PAulo MerêA e Rodrigo Otavio.

Estará a razão com o eminente professor da Universidade de Coimbra?

Parece-nos que não.

Comentando o art. 11 da Introdução, Clovis Bevilaqua deixou bem claro o seu pensamento, quando escreveu: 
“Não se deve, porém, supôr que a regra "locus regit actum" é obrigatoria. Desde que os individuos possam recorrer á forma da sua lei nacional, nada os impede de fazê-lo" (9).

Anos depois, em carta dirigida ao dr. Adelamar Tavares e publicada no "Jornal do Comércio" de 19 de setembro de 1921, dizia o eminente civilista patrio:

"Machado Vilela acha que a minha doutrina está em contradição com a fórmula da lei. Não lhe vejo razão. Em primeiro lugar, cumpre atender a que se trata de uma regra de direito internacional privado, para reger relações de membros da sociedade internacional e não um preceito de direito interno. As regras de direito internacional privado têm por fundamento esse principio superior de justiça, de que fala SAvigny, e se aplicam ás relações que se não realizam dentro do âmbito de um Estado; as regras da lei interna são expressões de uma autoridade constituida e se aplicam a relações circunscritas pela linha das fronteiras de cada Estado.

Quando o Codigo Civil estabelece uma regra de direito interno, impõe um preceito obrigatorio, fundado na soberania nacional, uma de cujas faces é o poder de ditar a lei para os habitantes do país; e quando estabelece uma regra de direito internacional privado já não fala com o mesmo imperio incontrastavel, porque o seu intuito é suprir deficiencias de um organismo juridico que não se desenvolve dentro dele, mas a seu lado, e é expressão da vida de uma sociedade, para a qual não há barreiras nacionais.

Sendo assim, não podemos interpretar o verbo "regerse-á" do art. 11 da Introdução do Codigo Civil, como um imperativo categorico, e, sim, como afirmação de que o Brasil acata a forma que estiver de acôrdo com a lei do lugar, onde $o$ ato juridico se realizar.

Esta é a interpretação, que, ao mesmo tempo, se harmoniza com a tradição liberal do nosso direito, e se coaduna 
com o conceito das tendencias do direito internacional privado.

Por outro lado, como V. observa, em outros dispositivos, a lei permite que os nossos concidadãos usem da forma estabelecida pelo direito patrio, quando se acharem no estrangeiro, o que evidencia que para o Codigo Civil a aplicação da regra "locus regit actum" não tem a inflexibilidade que o douto professor de Coimbra enxergou" (10).

Rodrigo Octavio, por seu turno, contestando a opinião que lhe é atribuida por Machado Vilela, depois de afirmar que a consagração do principio "locus regit actum" pelo artigo 11 da Introdução não o foi com caráter obrigatorio, assim se manifesta: "Vilela, á vista dos termos imperativos do texto, discorda desta restrição, entendendo que o dispositivo contém um mandamento obrigatorio, não sendo, assim, licito no Brasil a um estrangeiro o uso optativo de uma forma de sua lei nacional. Em apoio do seu modo de ver, o preclaro professor português invoca o meu trabalho "Conflit of laws in Brasil" 'Nesse trabalho, porém, eu não manifestei propriamente opinião a respeito, assinalei que "os termos da regra pareciam dar-lhe um caráter imperativo" e registrei a opinião nesse sentido do professor português Merêa, em seu Codigo Civil Brasileiro Anotado, e que Esprnola acompanha (anotações, pag. 195) (11) e a contrária de BEvilaqua, Vampré e João Luiz Alves, a que ainda se deve acrescentar a de Pontes de Mrranda (op. cit., pag. 486).

Parece-me, entretanto, que não se deve admitir o rigor de interpretação do eminente comentador, porisso que, se realmente os termos do dispositivo são peremptorios, neles não existe proibição de empregar outras fórmulas na facção do áto. E é nesse sentido que se tem formado a jurisprudencia liberal da justiça brasileira" (12).

Se, como vimos, a doutrina se mostra francamente favoravel ao caráter facultativo da regra "locus regit actum", com algumas poucas exceções, é verdade, a jurisprudencia de nossos tribunais tambem não lhe tem negado esse caráter, como se póde ver no recente "Dicionario de Direito. 
Internacional Privado", organizado pelo ministro Rodrigo Otavio.

Concluindo, pode-se, pois, afirmar que o principio "locus regit actum" foi admitido no Codigo Civil Brasileiro não com o caráter obrigatorio decorrente da forma imperativa com que está redigido o artigo 11 da Introdução, mas com o caráter facultativo, isto é, permitindo que a forma extrínseca dos atos publicos ou particulares poderá reger-se tanto pela lei do lugar em que forem os mesmos praticados, como pela lei nacional das partes interessadas.

Exposto o alcance do principio em nosso direito, seja-nos permitida uma rapida referencia ás vicissitudes do mesmo nas convenções internacionais.

$\mathrm{Na}$ primeira conferência de direito internacional privado reunida em Haya em 1893, a questão da forma externa dos atos foi submetida ás suas deliberações, e a comissão encarregada de estudar a matéria apresentou á conferência um ante-projeto que consagrava a regra "locus regit actum", que éra concebida nos seguintes termos: "A forma dos atos é regulada pela lei do lugar em que são feitos ou passados".

Embora os representantes da maioria dos Estados estivessem de acôrdo cơm a regra, entenderam, no entanto, que ela tinha um caráter demais abstrato para fazer parte de uma convenção internacional. E a regra não foi incluida no protocolo.

As sucessivas conferências não formularam uma regra geral nesse sentido, mas admitiram o principio em algumas convenções que foram concluidas, principalmente, em materia de casamento (artigo $5 .^{\circ}$ ).

No tratado de Montevidéo, concluido em 12 de Fevereiro de 1889 , foi expressamente consignada a regra "locus regit actum" (artigo 39). Deve-se observar, no entanto, que 
a regra somente se aplica aos atos publicos. Os atos privados estão submetidos á lei do lugar da execução do contrato que eles encerram.

O codigo de Direito Internacional privado de Havana. tambem conhecido pelo nome de Codigo Bustamante (13), não contém uma regra geral sobre a forma dos atos civis, mas no artigo 240 diz que "a forma dos contratos e atos comerciais é subordinada á lei territorial", não sendo de duvidar, como observa Audinet, que, na opinião dos que redigiram e votaram o Codigo, seja tambem aquela regra aplicavel aos atos civis.

(1) Como acentuamos em nossa dissertação "Da importancia da teoria dos estatutos no desenvolvimento do Direito Internacional Privado" além da regra "locus regit actum", tiveram a sua origem, entre os post-glosadores e a escola estatutaria, os principios relativos á lei reguladora do estado e capacidade das pessoas, atribuindo competencia á lei pessoal; á lei reguladora do regime dos bens imoveis, voluntarios dos atos juridicos, afirmando, por obra de Dumoulin, o principio da autonomia da vontade, e sôbre a forma do processo, decidindo-se pela competencia da lex fori.

(2) Eugène Audinet, no "Répertoire de Droit International", de Lapradelle e Niboyet, vol. X, pag. 389.

(3) Pillet et Niboyet, "Manuel de Droit International Privé" pag. 483.

(4) Buzzatr "L'autoritá delle leggi straniere relative alla forma degli atti civili” pag. 50.

(5) Pillet et Niboyet "Manuel" cit.

(6) Machado Vilela - O Direito Internacional Privado no Codigo Civil Brasileiro, pag. 225.

(7) Clovis Bevilaqua - Direito Internacional Privado, pags. 188-189.

(8) Codigo Civil Brasileiro, Trabalhos relativos á sua elaboração, vol. I, pag. 329.

(9) Clovis Bevilaqua - Codigo Civil Camentado, vol. I, pag. 129 da 2." edição. 
(10) Reproduzida no volume dedicado á Introdução (arts. 8 a 21) do "Manual do Codigo Civil Brasileiro", e da autoria do ministro RoDrigo Octravio.

(11) Nos seus "Elementos de Direito Internacional Privado,", a pag. 677, Eduardo Espinola manifesta opinião favoravel ao caráter facultativo da regra.

(12) Manual do Codigo Civil Brasileiro, vol. I - Parte II, pags. 324 .

(13) Aprovado pelo decreto n. 5647 de 7 de Janeiro de 1929. 